\title{
Comparison of emulsifying properties of milk fat globule membrane materials isolated from different dairy by-products
}

\author{
T. T. Q. Phan, ${ }^{* 1}$ T. T. Le,† P. Van der Meeren, $\ddagger$ and K. Dewettinck* \\ *Laboratory of Food Technology and Engineering, Department of Food Safety and Food Quality, Ghent University, Coupure Links 653 , \\ B-9000 Ghent, Belgium \\ †Department of Food Engineering, Faculty of Food Science and Technology, Nong Lam University, Thu Duc District, Ho Chi Minh City 70800 , \\ Vietnam \\ ‡Particle and Interfacial Technology Group, Faculty of Bioscience Engineering, Ghent University, Coupure Links 653, B-9000 Ghent, Belgium
}

\section{ABSTRACT}

Emulsifying properties of milk fat globule membrane (MFGM) materials isolated from reconstituted buttermilk (BM; i.e., BM-MFGM) and BM whey (i.e., wheyMFGM), individually or in mixtures with BM powder (BMP) were compared with those of a commercial dairy ingredient (Lacprodan PL-20; Arla Foods Ingredients Group P/S, Viby, Denmark), a material rich in milk polar lipids and proteins. The particle size distribution, viscosity, interfacial protein, and polar lipids load of oil-in-water emulsions prepared using soybean oil were examined. Pronounced droplet aggregation was observed with emulsions stabilized with whey-MFGM or with a mixture of whey-MFGM and BMP. No aggregation was observed for emulsions stabilized with BM-MFGM, Lacprodan PL-20, or a mixture of BMMFGM and BMP. The surface protein load and polar lipids load were lowest in emulsions with BM-MFGM. The highest protein load and polar lipids load were observed for emulsions made with a mixture of wheyMFGM and BMP. The differences in composition of MFGM materials, such as in whey proteins, caseins, MFGM-specific proteins, polar lipids, minerals, and especially their possible interactions determine their emulsifying properties.

Key words: milk fat globule membrane, emulsifying property, emulsion

\section{INTRODUCTION}

Emulsifying properties of milk-derived components influence the physicochemical characteristics of dairy emulsions. Skim milk powder, sweet buttermilk (BM) powder, butter-derived serum phase, whey proteins, casein dispersions, phospholipids, and purified milk fat

Received February 6, 2014.

Accepted April 19, 2014.

${ }^{1}$ Corresponding author: thithanhque.phan@ugent.be or pttque@ ctu.edu.vn globule membrane (MFGM) suspensions have been successfully used to make emulsions (Tomas and Paquet, 1994; Elling et al., 1996; McCrae et al., 1999).

In recent years, interest has increased in gathering knowledge on the composition and properties of MFGM materials. Milk fat globule membrane materials are found in quite significant amounts in different dairy products, such as cream, butter, BM, BM whey, and cheese. The unique functionality of MFGM-enriched materials has led to research and development of techniques to isolate, purify, and apply the materials in different food emulsions (Singh, 2006). The serum phase as by-product from churning cream into butter is known as BM. It is rich in MFGM fragments and contains all water-soluble components from the milk, such as lactose, caseins, and whey proteins. Buttermilk whey is obtained from BM after coagulating and removing casein micelles, a process applied in production of some special cheese and in caseinate manufacturing. Buttermilk whey still contains some residual fat and consists of lipoprotein particles, MFGM fragments, and small fat globules (Rombaut and Dewettinck, 2007b). Proper utilization of these cheap by-products to isolate the functional MFGM material and subsequent application of the material in the development of new products has great economic and technological value. Besides some by-products of the dairy industry, Lacprodan PL-20 (Arla Foods Ingredients Group P/S, Viby, Denmark) is a dairy formulation enriched with polar lipids and proteins. It has potential as a market alternative to semisynthetically head-group-exchanged soy phospholipids because it is a natural source for phosphatidylserine. Moreover, Lacprodan PL-20 can be used as an active health ingredient in functional foods, such as drinks, ice creams, and chocolate (Burling and Graverholt, 2008).

According to the results of Corredig and Dalgleish (1997), MFGM-enriched materials isolated from industrial BM were poor emulsifiers for soy oil-in-water emulsions compared with those isolated from fresh cream. The type of starting material, pretreatment, and method of separation have a significant effect on 
the composition of MFGM isolates and, consequently, on their emulsifying properties (Kanno, 1989; Kanno et al., 1991). Wong and Kitts (2003) as well as Corredig and Dalgleish (1997) found that commercial BM had inferior emulsifying and stabilizing capacity compared with nonfat dried milk. Roesch et al. (2004) studied the emulsifying properties of commercial BM powder (BMP) and the MFGM fragments obtained by microfiltration (MF) of reconstituted BM. The emulsions made with the MFGM isolate were found to have good stability against creaming; the small particle size distribution pattern increased with MFGM concentration, whereas a similar emulsion prepared with BM concentrate showed extensive flocculation. Phan et al. (2013) also found that MFGM fragments concentrated from reconstituted $\mathrm{BM}$ using $\mathrm{MF}$ had better emulsifying and stabilizing properties compared with BMP, skim milk powder, and sodium caseinate.

From the reports cited above, it appears that processing conditions in dairy processing influence differently the nature of MFGM materials in the derived by-products and that their MFGM isolates differ in composition (of polar lipids and proteins) and in their technological functionalities. Milk fat globule membrane-specific proteins are amphiphilic molecules that can act as surface-active compounds (Singh, 2011). Polar lipids are also known to be good emulsifiers (Kanno, 1989; Dewettinck et al., 2008). Many investigators have been successful in isolating MFGM fragments, which contain high concentrations of polar lipids and specific membrane proteins, from by-products of dairy industrial processing. However, whether proteins or polar lipids are responsible for the emulsifying activity is unclear. The competitive adsorption between the proteins and polar lipids at the interface during emulsification has not been studied. It is also unclear how the emulsifying properties are modified by possible interactions between MFGM materials and other components (e.g., whey proteins, caseins, and minerals). To get a better understanding of the role of MFGM components, in the current study, the properties of emulsions made with different MFGM materials and mixtures of MFGM and the initial material (BMP) were investigated.

\section{MATERIALS AND METHODS}

\section{Materials}

Buttermilk powder was obtained from FrieslandCampina (Lummen, Belgium). Buttermilk whey was obtained from a local dairy company (Büllinger Butterei NV, Büllinger, Belgium). Lacprodan PL-20 (a spray-dried powder, rich in milk phospholipids and proteins) was kindly provided by Arla Foods
Ingredients Group P/S. Soybean oil was purchased from a local supermarket.

\section{Isolation of the MFGM Materials}

Reconstituted BM was prepared according to Le et al. (2011b). Trisodium citrate (1\%, wt/wt) was added to dissociate casein micelles into casein components that were small enough to permeate the membrane during the filtration process (Corredig et al., 2003; Rombaut et al., 2006). For BM whey, the $\mathrm{pH}$ was adjusted to 7.5 by adding $1 \mathrm{~N} \mathrm{KOH}$ before MF (Rombaut et al., 2007a). Cross-flow MF was performed in combination with continuous diafiltration (the rate of water addition was equal to the permeate rate) to separate the MFGM fragments from the 2 materials (reconstituted BM and BM whey; Phan et al., 2013). The materials obtained from reconstituted $\mathrm{BM}$ and $\mathrm{BM}$ whey after $\mathrm{MF}$ were designated BM-MFGM and whey-MFGM, respectively. The BM-MFGM and whey-MFGM were freeze-dried (VaCo 5-D; Zirbus Technology GmbH, Bad Grund, Germany) to obtain a water-free MFGM-enriched powder. For further analysis and emulsion preparation, the MFGM-enriched powder was stored below $-20^{\circ} \mathrm{C}$.

\section{Compositional Analysis}

The DM content of the experimental materials was determined by gravimetric difference after heating at $105^{\circ} \mathrm{C}$ (IDF, 2004). The total protein content of the samples was determined by the Kjeldahl method (IDF, 1993) using 6.38 as a conversion factor. The RöseGottlieb method (gravimetric determination) was used to determine the total fat content (IDF, 1986). Total ash content of the samples was determined according to the procedure of the Association of Official Analytical Chemists (AOAC, 1984). The polar lipids were extracted and analyzed according to the method of Le et al. (2011a), using a Shimadzu HPLC system (Shimadzu Corp., Tokyo, Japan) with an evaporative light-scattering detector (Alltech-3300; Alltech Associates Inc., Lokeren, Belgium). The method and the calculations used to determine protein using SDS-PAGE have been described by Le et al. (2009) and Phan et al. (2013).

\section{Emulsion Preparation}

To compare the emulsifying properties of MFGM material and the interaction between MFGM material and other components (caseins and whey proteins) the following materials were used to stabilize oil-in-water emulsions [35\% (wt/wt) soybean oil]: BM-MFGM, whey-MFGM, Lacprodan PL-20, or mixtures composed of the MFGM material and BMP. For emulsions pre- 
Table 1. Composition in weight percentage of prepared emulsions [all contained $35 \%$ (wt/wt) soybean oil] ${ }^{1}$

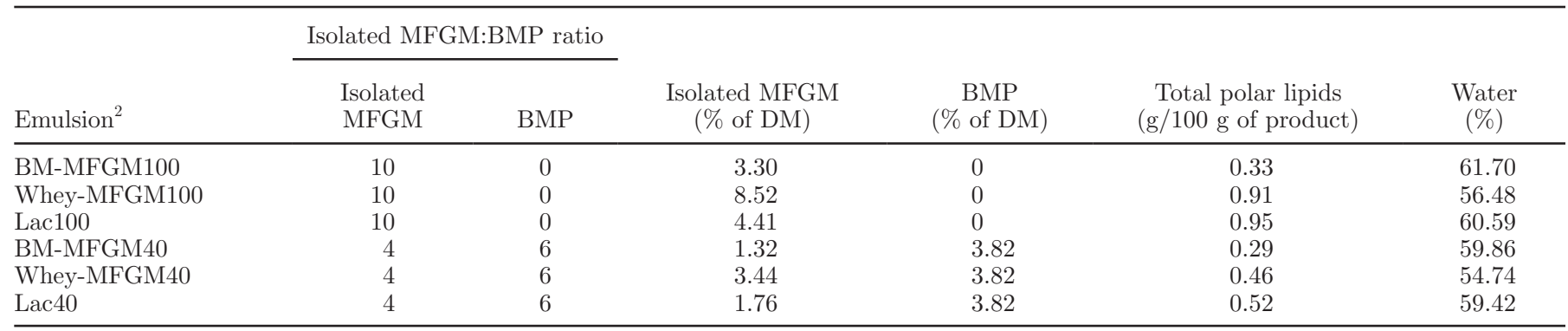

${ }^{1} \mathrm{MFGM}=$ milk fat globule membrane; $\mathrm{BM}=$ buttermilk; $\mathrm{BMP}=\mathrm{BM}$ powder.

${ }^{2}$ BM-MFGM100 = emulsion with microfiltered BM alone as the emulsifier; whey-MFGM100 = emulsion with microfiltered BM whey alone as the emulsifier; Lac100 = emulsion with Lacprodan PL-20 (Arla Foods Ingredients Group P/S, Viby, Denmark) alone as the emulsifier; BMMFGM40 = emulsion with mixture of microfiltered BM and BMP (4:6, wt/wt); whey-MFGM40 = emulsion with mixture of microfiltered BM whey and BMP (4:6, wt/wt); Lac40 = emulsion with mixture of Lacprodan PL-20 and BMP (4:6, wt/wt).

pared with a mixture of the MFGM material and BMP, a ratio of $4: 6$, based on the dry weight of the former to the latter, was used due to practical considerations. Actually, results of the screening test showed no significant difference between the ratios 4:6 and 5:5. The supplement of the emulsifying materials was calculated to have the same concentration of total protein (2.3 $\mathrm{g} / 100 \mathrm{~g}$ of product). Table 1 illustrates the composition of the emulsions prepared for the experiments.

To prepare emulsions, powders were dissolved in deionized water using a magnetic stirrer and stored overnight at $4^{\circ} \mathrm{C}$ for complete hydration. After adding soybean oil to the serum phase, the $\mathrm{pH}$ was adjusted to 7.0 by adding $0.1 \mathrm{M} \mathrm{KOH}$. The mixture was heated to $50^{\circ} \mathrm{C}$ and prehomogenized using an ULTRA-Turrax T25 basic disperser (IKA-Werke GmbH \& Co. KG, Staufen, Germany) at 13,000 rpm for $2 \mathrm{~min}$. The homogenization was performed in a 2-step laboratory-scale high-pressure homogenizer (APV Cooling Systems, Albertslund, Denmark) at 9 and $2 \mathrm{MPa}$ for the first and second step, respectively. After the homogenization, the emulsions were stored at $4^{\circ} \mathrm{C}$ before analysis. Emulsions were prepared in triplicate.

\section{Measurement of Particle Size Distribution}

After $1 \mathrm{~d}$ of storage at $4^{\circ} \mathrm{C}$, the emulsion was dispersed at $1 \%$ in water or in $1 \%$ SDS solution before the measurement of the particle size distribution (Ye et al., 2004). The measurement was carried out using a long bench Malvern Mastersizer S (Malvern Instruments Ltd., Malvern, UK) equipped with an MS17 automated sample dispersion unit. The polydisperse analysis of the samples was carried out using a $300 \mathrm{RF}$ lens and the standard presentation code $(1.5295,0.01$, and 1.3300 for the particle refractive index, particle absorption, and dispersant refractive index, respectively; Phan et al., 2013). The Sauter mean diameter $\left(\mathbf{d}_{\mathbf{3}, 2}\right)$ was used to compare the emulsion droplet sizes. The measurements were carried out in triplicate for each sample and average values were determined.

\section{Microscopic Observation}

Microscopic observation of the emulsions was carried out according to Phan et al. (2013). Samples were first diluted 10 times in deionized water and a drop of the sample was carefully placed on a glass slide, covered with a coverslip, and observed at $50 \times$ magnification using a Leitz Diaplan microscope (Leica Mikrosysteme Vertrieb GmbH, Wetzlar, Germany). The images were recorded with a built-in Olympus Color View camera and processed with cell D software (Olympus Belgium NV, Aartselaar, Belgium).

\section{Rheological Characteristics}

The rheological characteristics of the samples were measured after $1 \mathrm{~d}$ of storage at $4^{\circ} \mathrm{C}$ using a TA Instruments AR2000 controlled-stress rheometer (TA Instruments Inc., New Castle, DE), equipped with a conical concentric cylinder geometry (28-mm diameter) and a cup (30-mm diameter). The sample (20 g) was weighed in the cup of the rheometer for the measurements.

Flow curves were measured with increasing shear rates ( 0.1 to $100 \mathrm{~s}^{-1} ; 31$ measuring points), at a temperature of $20^{\circ} \mathrm{C}$. The experimental data were fitted to the power law equation:

$$
\text { Shear stress }=\mathrm{K} \times(\text { shear rate })^{\mathrm{n}} \text {, }
$$

where $\mathrm{K}$ is the consistency index and $\mathrm{n}$ is the flow behavior index. 


\section{Determination of Surface Protein Load, Polar Lipids Load, and the Adsorption Behavior of Proteins at the Oil-Water Interface}

Emulsions (25 g) were weighed into a plastic centrifugation tube, capped, and centrifuged at 12,000 $\times$ $g$ for $45 \mathrm{~min}$ at $20^{\circ} \mathrm{C}$ using a Sigma $4 \mathrm{~K} 15$ centrifuge (Sartorius AG, Göttingen, Germany). The serum phase (bottom layer) was carefully removed using a syringe. The cream phase (top layer) was dispersed into deionized water and recentrifuged at 12,000 $\times g$ for $45 \mathrm{~min}$ as in the previous step. The serum phase was again removed. The mixture of serum phase was filtered through $0.45 \mu \mathrm{m}$ and $0.2 \mu \mathrm{m}$ cellulose acetate filters (Whatman, Freiburg, Germany).

The surface protein load $\left(\boldsymbol{\Gamma}_{\text {Pro }} ; \mathrm{mg} / \mathrm{m}^{2}\right)$ of emulsions was carried out according to Ye (2010), with some modification. The adsorbed protein content (cream phase; g) was determined by the Kjeldahl method (IDF, 1993) using 6.38 as the conversion factor. To determine the surface polar lipids load $\left(\boldsymbol{\Gamma}_{\mathrm{PL}} ; \mathrm{mg} / \mathrm{m}^{2}\right)$, the polar lipids in the cream phase $(\mathrm{g})$ were extracted and analyzed as described in the Compositional Analysis section.

The total fat surface area $\left(\mathrm{m}^{2}\right)$ was derived from the $\mathrm{d}_{3,2}$. The $\Gamma_{\text {Pro }}$ and $\Gamma_{\text {PL }}$ were calculated from Equations [2] and [3], respectively:

$$
\begin{aligned}
\Gamma_{\text {Pro }}= & \text { total protein adsorbed }(\mathrm{mg}) / \\
& \text { total fat surface area }\left(\mathrm{m}^{2}\right) ; \\
\Gamma_{\mathrm{PL}}= & \text { total polar lipids adsorbed }(\mathrm{mg}) / \\
& \text { total fat surface area }\left(\mathrm{m}^{2}\right) .
\end{aligned}
$$

The protein profile in the emulsions, the individual adsorbed protein (i.e., top layer) at the surface of the oil droplets, and the nonabsorbed protein in the serum phase (i.e., bottom layer) were determined using SDSPAGE. The XCell SureLock Mini-Cell Electrophoresis System, all reagents, and the gradient gels (Novex NuPAGE 4-12\% Bis-Tris $1 \mathrm{~mm} \times 17$ wells) were purchased from Invitrogen (Merelbeke, Belgium). Samples were prepared as described by Le et al. (2009) with some modifications. To avoid vertical streaks appearing on the gel after staining, the samples were partially defatted before reducing and loading on gel. Defatting was performed by using a 20:1 (vol/vol) dichloromethane:methanol mixture to dilute the sample in an Eppendorf tub, which was then repeated vortexing for approximately $20 \mathrm{~s}$. The suspension was centrifuged at $1,680 \times g$ for $60 \mathrm{~s}$ at $20^{\circ} \mathrm{C}$ and the dichloromethane (lower phase) was removed. The sample was dried by flushing with nitrogen gas and redissolved in distilled water by sonication. The load on each sample lane was $16 \mu \mathrm{g}$ of total protein. Electrophoresis was performed according the protocol of Invitrogen with SimplyBlue SafeStain (Coomassie Blue). The wet gel was scanned at 400 dots per inch (dpi) using a high-resolution transmission scanner (UMAX PowerLook III; UMAX Technologies, Taipei, Taiwan). The different types of proteins were identified by comparing the protein bands with the molecular weight of Mark12 Protein Standard (Invitrogen). The band intensities of proteins in the emulsion, cream phase, and serum phase were compared. The proportion of individual protein [xanthine oxidase (XO), butyrophilin (BTN), caseins, $\beta-\mathrm{LG}$, and $\alpha-\mathrm{LA}]$ at the surface of the oil droplets (i.e., cream phase) and individual protein in the emulsion (i.e., in the cream phase + in the serum phase) were calculated using densitometry on SDS-PAGE according to the following equation:

Surface protein proportion $(\%)=$ intensity of protein (XO, BTN, casein, $\beta-\mathrm{LG}$, or $\alpha-\mathrm{LA}$ ) band in cream phase intensity of protein (XO, BTN, casein, $\beta$-LG, or $\alpha$-LA) band in cream and serum phases

\section{Statistical Analysis}

A statistical analysis was performed using the S-Plus 8.0 software package for Windows (Tibco Software Inc., Palo Alto, CA). One-way ANOVA and the Tukey test were used for multiple comparisons of means. The differences were considered statistically significant at $P$ $\leq 0.05$.

\section{RESULTS AND DISCUSSION}

\section{Composition of the Experimental Materials}

The composition of the different experimented materials is shown in Table 2. We found that the composition of the experimental materials was significantly different from each other. Whey-MFGM contained the highest 
Table 2. Composition of the emulsifying materials expressed as percentages on a DM basis ${ }^{1}$

\begin{tabular}{|c|c|c|c|c|c|}
\hline Material $^{2}$ & $\begin{array}{c}\text { Total } \\
\text { protein }\end{array}$ & $\begin{array}{l}\text { Casein:whey } \\
\text { protein ratio }\end{array}$ & $\begin{array}{l}\text { Total } \\
\text { lipids }\end{array}$ & Ash & $\begin{array}{l}\text { Polar } \\
\text { lipids }\end{array}$ \\
\hline $\begin{array}{l}\text { BMP } \\
\text { BM-MFGM } \\
\text { Whey-MFGM } \\
\text { Lacprodan PL-20 }\end{array}$ & $\begin{array}{l}34.25 \pm 0.14^{\mathrm{b}} \\
69.63 \pm 1.30^{\mathrm{d}} \\
26.50 \pm 1.19^{\mathrm{a}} \\
52.22 \pm 1.27^{\mathrm{c}}\end{array}$ & $\begin{array}{l}1.75 \pm 0.01^{\mathrm{d}} \\
1.02 \pm 0.02^{\mathrm{b}} \\
0.14 \pm 0.01^{\mathrm{a}} \\
1.26 \pm 0.08^{\mathrm{c}}\end{array}$ & $\begin{array}{r}8.37 \pm 0.30^{\mathrm{a}} \\
23.80 \pm 0.61^{\mathrm{b}} \\
39.01 \pm 0.20^{\mathrm{d}} \\
31.10 \pm 0.57^{\mathrm{c}}\end{array}$ & $\begin{array}{r}7.13 \pm 0.05^{\mathrm{c}} \\
3.25 \pm 0.17^{\mathrm{a}} \\
23.39 \pm 0.31^{\mathrm{d}} \\
6.46 \pm 0.10^{\mathrm{b}}\end{array}$ & $\begin{array}{r}3.27 \pm 0.13^{\mathrm{a}} \\
9.30 \pm 0.31^{\mathrm{b}} \\
12.10 \pm 0.19^{\mathrm{c}} \\
23.10 \pm 0.70^{\mathrm{d}}\end{array}$ \\
\hline \multicolumn{6}{|c|}{$\begin{array}{l}\frac{\mathrm{a}-\mathrm{d}}{} \text { Values within a column followed by different superscript letters are significantly different (Tukey test, } P \leq \\
0.05) \text {. } \\
{ }^{1} \text { Values } \pm \text { SD of } 3 \text { replicates. } \\
{ }^{2} \mathrm{BMP}=\text { buttermilk }(\mathrm{BM}) \text { powder; BM-MFGM = microfiltered BM milk fat globule membrane (MFGM) } \\
\text { whey-MFGM = microfiltered BM whey; Lacprodan PL-20 was from Arla Foods Ingredients Group P/S (Viby } \\
\text { Denmark). } \\
{ }^{3} \text { The casein:whey protein ratio is a relative estimation using densitometry. }\end{array}$} \\
\hline
\end{tabular}

amount of total lipids (39.01 g/100 g), whereas polar lipids were most abundant in Lacprodan PL-20 (23.10 $\mathrm{g} / 100 \mathrm{~g})$. According to the manufacturer of this material, it has a minimum phospholipids content of $16 \%$, a maximum ash content of $6 \%$, and a protein content of 49 to $55 \%$. The analyses in this study resulted in similar results (Table 2). Among the 4 materials, whey-MFGM had the highest amount of ash $(23.39 / 100 \mathrm{~g})$ and the lowest protein content $(26.50 \mathrm{~g} / 100 \mathrm{~g})$. The low protein content was due to the fact that large amounts of proteins, mainly caseins, were already coagulated and precipitated during cheese making (Vanderghem et al., 2010). The addition of calcium chloride as process additive during cheese making results in the high ash content of the BM whey as well as the derived MFGM isolate (Rombaut et al., 2007a). It can also be seen in Table 2 that the ratio of caseins to whey proteins in the whey-MFGM material was clearly the lowest among all materials.

Compared with the beginning material (BMP) BMMFGM contained more proteins $(69.63 \mathrm{~g} / 100 \mathrm{~g})$, lipids $(23.80 \mathrm{~g} / 100 \mathrm{~g})$, and polar lipids $(9.30 \mathrm{~g} / 100 \mathrm{~g})$. The difference in composition of those materials was already discussed elsewhere (Phan et al., 2013).

Based on densitometry, the band intensity of XO of Lacprodan PL-20 (lane 2) was similar to that of BM-MFGM, whereas the band intensity of BTN of BM-MFGM (lane 3) was found to be 1.2 times higher than that of Lacprodan PL-20. Among the 4 materials, band intensities of the major MFGM-specific proteins of whey-MFGM were faint or even not distinguishable (lane 4). In addition to MFGM-specific proteins, nonMFGM proteins, such as caseins and whey proteins, were found to be present up to a considerable amount in BMP, BM-MFGM, and Lacprodan PL-20 (Figure $1)$. However, the ratio of casein to whey proteins was significantly different among the 4 materials (Table 2).

\section{Particle Size Distribution}

In Figure 2, the droplet size distribution of different emulsions is shown. In Table 3 , the $\mathrm{d}_{3,2}$ of emulsions prepared with different emulsifying materials after dilution in water or in $1 \%$ SDS solution is given.

The effect of different MFGM materials and mixtures of individual MFGM material and BMP on droplet size distribution is shown in Figure 2. Measured after diluting in water, the emulsions of microfiltered BM (BM-MFGM100), Lacprodan PL-20 (Arla Foods Ingredients Group P/S, Viby, Denmark; Lac100), and a mixture of microfiltered BM and BMP (4:6, wt/wt; BM-MFGM40) had a narrower particle size distribution pattern compared with that of the emulsions of microfiltered BM whey (whey-MFGM100), mixture of microfiltered BM whey and BMP (4:6, wt/wt; wheyMFGM40), and mixture of Lacprodan PL-20 and $\operatorname{BMP}$ (4:6, wt/wt; Lac40). Sodini et al. (2006) found that better emulsifying properties can be obtained with a higher ratio of phospholipids to proteins. In the present study, a wider particle size distribution was found in the emulsion prepared with a high content of polar lipids (i.e., whey-MFGM100), whereas the emulsion prepared with BM-MFGM (regardless the concentration), containing the lowest polar lipid content (Table 1), had a narrower particle size distribution. This may indicate that some other factors interacted with the adsorption process at the droplet surface. Corredig and Dalgleish (1997) found that emulsion stability strongly depends on the type of isolate that was used. The isolate that contained only MFGM fragments was a poor emulsifier compared with the isolate containing whey proteins, caseins, and MFGM-specific proteins. Whey-MFGM contains the lowest level of caseins and MFGM proteins, as evidenced by the MFGM protein pattern in the SDSPAGE (Figure 1). The absence of casein strongly influenced the emulsifying behavior. Corredig and Dalgleish (1998) reported that when BMP was used to prepare oil-in-water emulsions, caseins made up about $50 \%$ of the total proteins adsorbed at the interface. Cano-Ruiz and Richter (1997) also showed that caseins and whey proteins covered the surface of the fat globules when they were homogenized, leading to an increase in their 


\section{$\begin{array}{lllll}1 & 2 & 3 & 4 & 5\end{array}$}

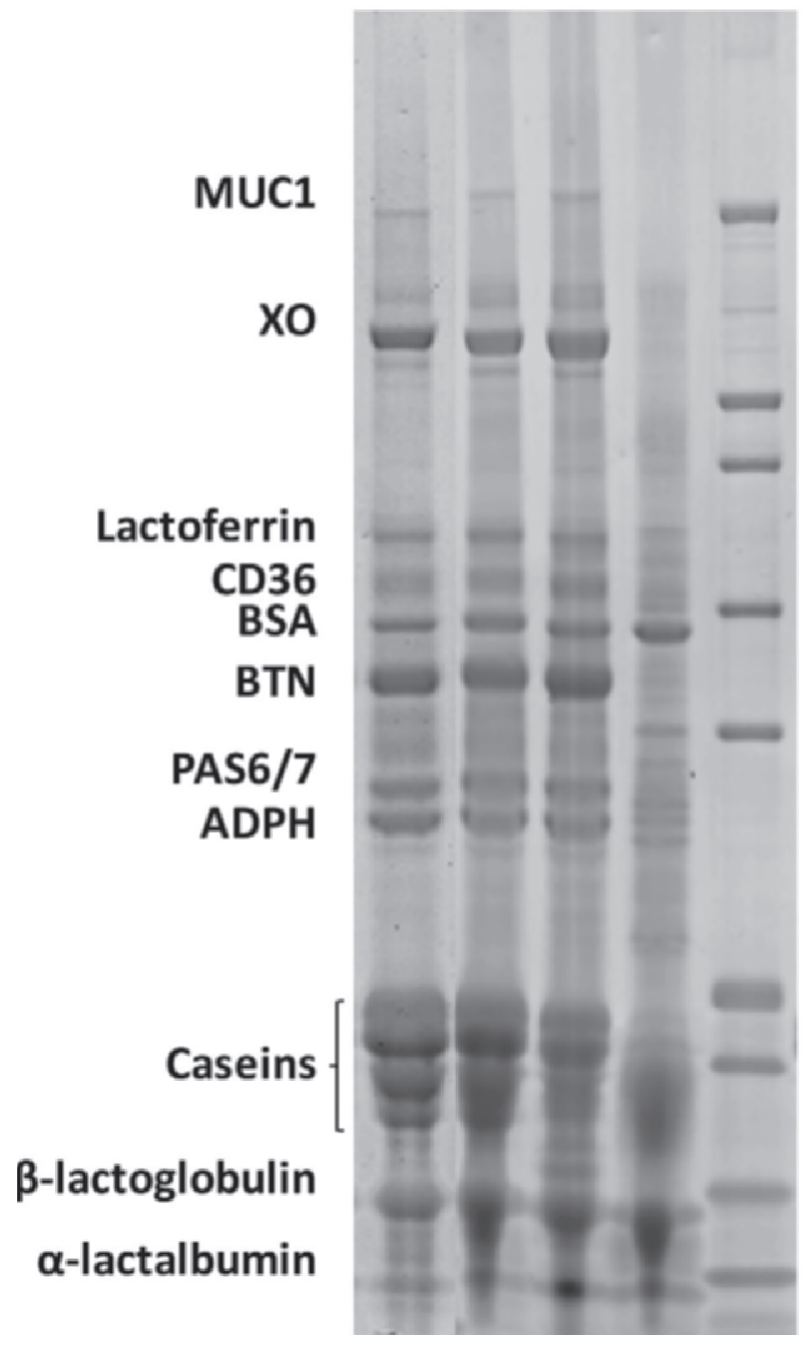

200

116

97

66

55

36

31

21

14

groups and can bridge caseins together, or bridge 2 negative groups of a protein. This can give rise to protein aggregation. Moreover, no visible phase separation was observed in emulsion whey-MFGM100 (data not shown).

Table 3 shows that the $\mathrm{d}_{3,2}$ of emulsions prepared with different emulsifying materials, after dilution in water, was significantly different. The emulsions of BMMFGM100, Lac100, and BM-MFGM40 had a smaller droplet size compared with those of whey-MFGM100, whey-MFGM40, and Lac40.

The $\mathrm{d}_{3,2}$ of emulsions of whey-MFGM100, wheyMFGM40, or Lac40 diluted in water was found to be larger than that of emulsions diluted in 1\% SDS (Table 3 ). In the presence of SDS, disintegration of emulsion droplet aggregates occurred, displacing the protein aggregates with the surfactant molecules (SDS). When an emulsion is diluted in an SDS solution, it is possible to determine the size distribution of the individual fat droplets and not the aggregated or flocculated ones (Roesch et al., 2004). The result was confirmed by the data on the stability of emulsions. All emulsions prepared with different emulsifying materials showed no separation after $14 \mathrm{~d}$ of storage at $4^{\circ} \mathrm{C}$ (figure not shown).

In general, it can be concluded that emulsions prepared with different ingredients showed different emulsifying behaviors. The droplet size of emulsions was not only affected by the higher participation of polar lipids, but also by the presence of other components, such as whey proteins, caseins, MFGM-specific proteins, and minerals.

\section{Microscopic Observation}

Differences in the degree of flocculation of emulsions prepared with different MFGM materials or a mixture of individual MFGM material and BMP (4:6, wt/ wt) can be seen in Figure 3. Microscopic examination showed that emulsion whey-MFGM100 contained many aggregates (Figure 3B). This result was in agreement with the data on the particle size distribution. Wong and Kitts (2003) reported that not the MFGM components but rather the ratio between the casein, whey, and MFGM content in BM determines its functional properties. In addition, whey-MFGM has a very low amount of MFGM-specific proteins, especially XO and BTN (Figure 1). Vanderghem et al. (2010) reported that the membrane-specific proteins may have good emulsifying properties and be responsible for emulsion stability.

Despite the fact that the level of MFGM proteins (mainly XO and BTN) and the casein:whey protein ratio of emulsions whey-MFGM40 was higher compared 
Table 3. Sauter mean diameter ${ }^{1}\left(d_{3,2}\right)$ of emulsions prepared with different emulsifying materials after dilution in water or in $1 \%$ SDS solution

\begin{tabular}{lcc}
\hline Emulsion $^{2}$ & In water & In SDS \\
\hline BM-MFGM100 & $1.44 \pm 0.04^{\mathrm{a}}$ & $1.20 \pm 0.30^{\mathrm{a}}$ \\
Whey-MFGM100 & $5.87 \pm 0.01^{\mathrm{d}}$ & $1.15 \pm 0.01^{\mathrm{a}}$ \\
Lac100 & $2.09 \pm 0.05^{\mathrm{b}}$ & $1.67 \pm 0.02^{\mathrm{b}}$ \\
BM-MFGM40 & $2.08 \pm 0.03^{\mathrm{b}}$ & $1.63 \pm 0.03^{\mathrm{b}}$ \\
Whey-MFGM40 & $6.22 \pm 0.04^{\mathrm{e}}$ & $2.10 \pm 0.08^{\mathrm{c}}$ \\
Lac40 & $4.40 \pm 0.15^{\mathrm{c}}$ & $1.69 \pm 0.01^{\mathrm{b}}$ \\
\hline
\end{tabular}

${ }^{\mathrm{a} e}$ Values within a row followed by different superscript letters are significantly different (Tukey test, $P \leq 0.05$ ).

${ }^{1}$ Data are expressed as mean values $\pm \mathrm{SD}$ of 3 replicates.

${ }^{2}$ BM-MFGM100 = emulsion prepared with microfiltered buttermilk (BM) milk fat globule membrane (MFGM); whey-MFGM100 = emulsion with microfiltered BM whey; Lac100 = emulsion with Lacprodan PL-20 (Arla Foods Ingredients Group P/S, Viby, Denmark); BMMFGM40 = emulsion with mixture of microfiltered BM and BMP $(4: 6, \mathrm{wt} / \mathrm{wt})$; whey-MFGM40 = emulsion with mixture of microfiltered BM whey and BMP (4:6, wt/wt); Lac40 = emulsion with mixture of Lacprodan PL-20 and BMP (4:6, wt/wt).

with that of emulsions whey-MFGM100, many large aggregates were observed in the latter emulsion (Figure $3 \mathrm{E})$. This could probably be due to the fact that binding of $\mathrm{Ca}^{2+}$ to the casein-coated oil droplets resulted in aggregation of emulsion droplets. Swaisgood (1992) reported that the binding of $\mathrm{Ca}^{+2}$ to phosphoserine in caseins reduces the electrostatic repulsions between the casein molecules, which could promote interactions between hydrophobic domains, leading to formation of aggregates.

Microscopic comparison of emulsions Lac100 and Lac40 (Figure 3C and 3F) showed that Lac100 was a better emulsifier than Lac40, probably due to the difference in the level of polar lipids present (Table 1). In addition, the BMP used in this study was heat treated during the previous production. Excessive heat denaturation may impair the emulsifying properties by rendering the protein insoluble (Voutsinas et al., 1983). With the same BMP concentration added, emulsion Lac40 contained more aggregates than emulsion BM-MFGM40. According to Scholey et al. (2013), Lacprodan PL-20 is a milk protein concentrate rich in natural, nonsynthetic milk phospholipids. It could probably contain more casein aggregates in the constituent proteins, resulting in less efficient functionality as emulsifier.

Microstructural observation of emulsions prepared with BM-MFGM alone as emulsifier (i.e., BMMFGM100) showed the presence of individual oil droplets and no sign of aggregation (Figure 3A), which was not much different from what was observed with Lac100 and BM-MFGM40 emulsions (Figure 3C and $3 \mathrm{D})$. In emulsifying materials, many other substances, such as whey proteins, caseins, MFGM proteins, polar lipids, and minerals, are present in different concentrations, which may influence the stability of oil-in-water emulsions. The effect of these components as well as of their concentrations still needs further investigation.

\section{Rheological Behavior}

The curves of shear stress versus shear rates are plotted in Figure 4. The power law model fit the data well $(P<0.05)$. The parameters of the different emulsifying
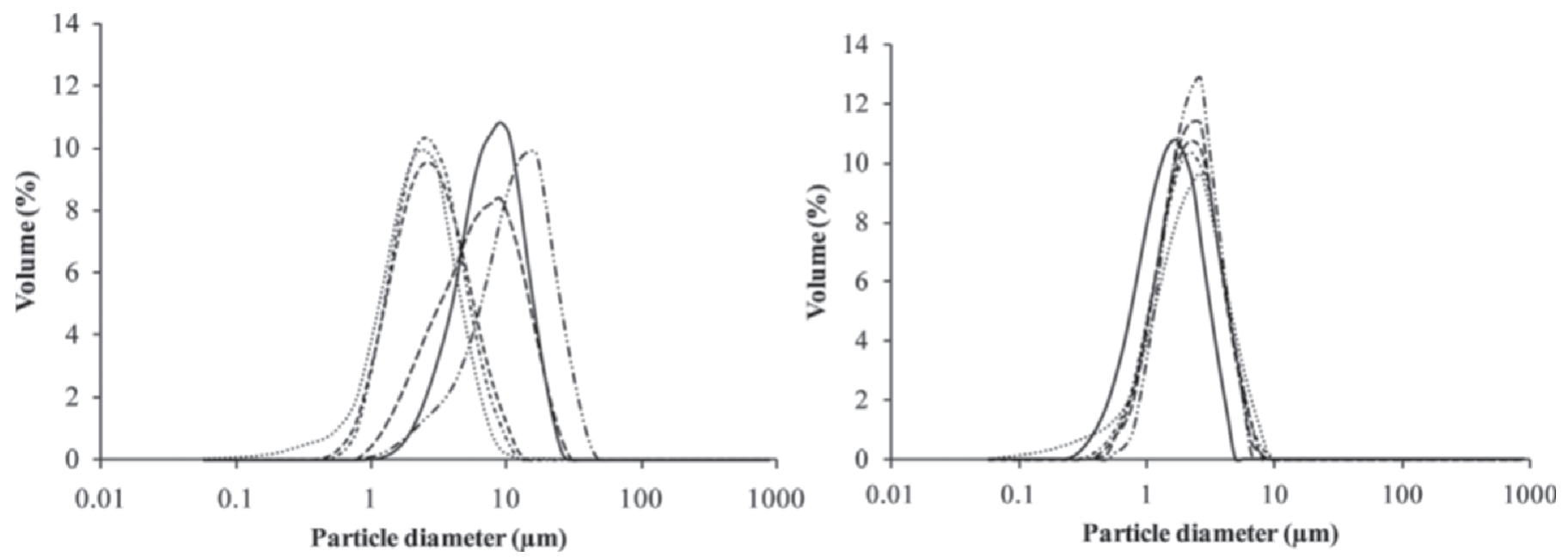

Figure 2. Particle size distribution of emulsions prepared with microfiltered buttermilk [buttermilk (BM) milk fat globule membrane (BMMFGM100); …], microfiltered BM whey (whey-MFGM100; -), Lacprodan PL-20 (Lac100; Arla Foods Ingredients Group P/S, Viby, Denmark; ----), mixture of microfiltered BM and BM powder $(4: 6, \mathrm{wt} / \mathrm{wt}$; BM-MFGM40; - - - ), mixture of microfiltered BM whey and BM powder (4:6, wt/wt; whey-MFGM40; - - - - ), and mixture of Lacprodan PL-20 and BM powder (4:6, wt/wt; Lac40; - - ). The measurements were carried out after dilution in water (left) or in $1 \%$ SDS (right). 

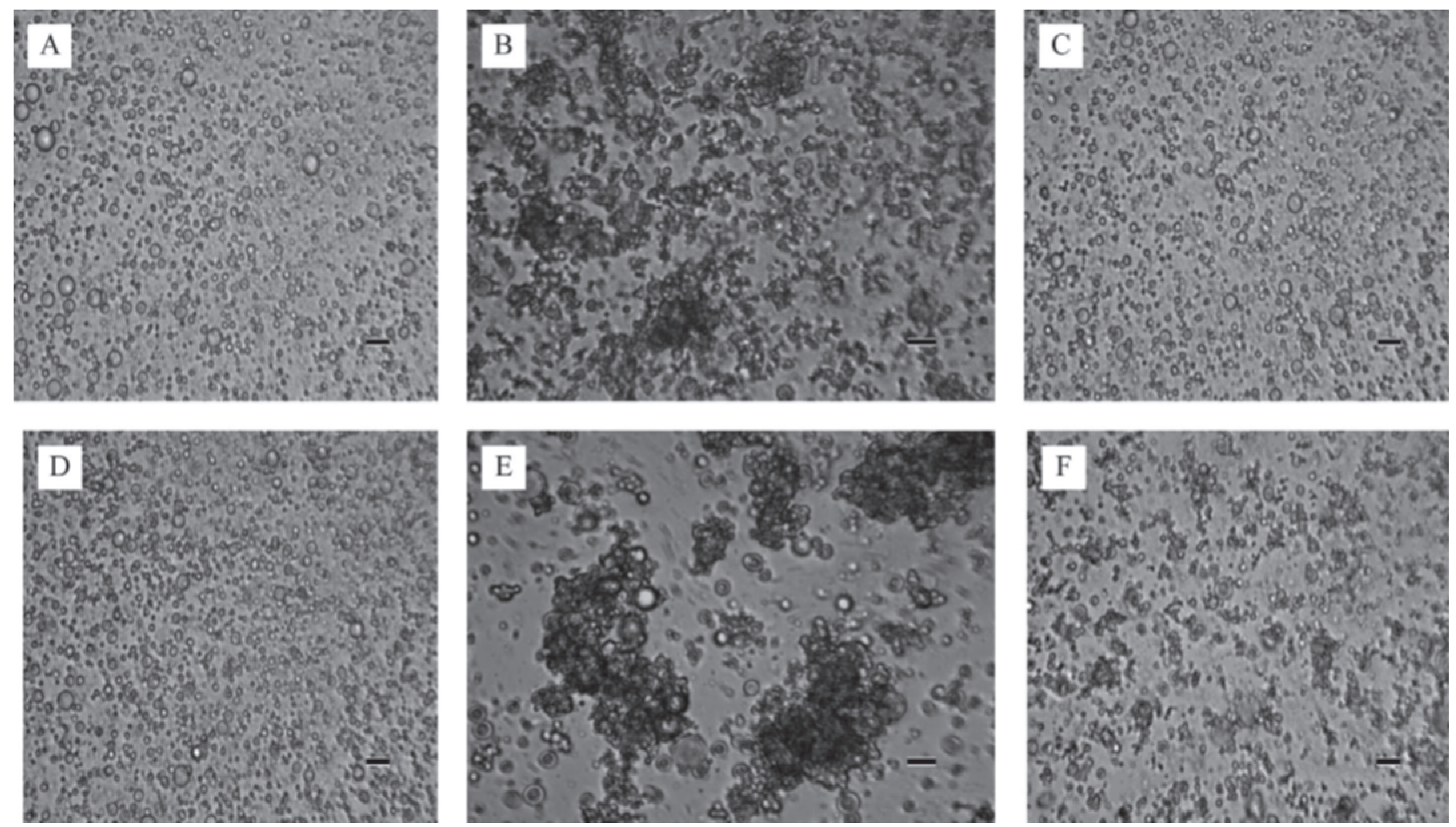

Figure 3. Microscopic images of emulsions prepared with different emulsifying materials. $\mathrm{A}=$ microfiltered buttermilk [buttermilk (BM) milk fat globule membrane (BM-MFGM100)]; B = microfiltered BM whey (whey-MFGM100); C = Lacprodan PL-20 (Lac100; Arla Foods Ingredients Group P/S, Viby, Denmark); D = mixture of microfiltered BM and BM powder (4:6, wt/wt; BM-MFGM40); E = mixture of microfiltered BM whey and BM powder (4:6, wt/wt; whey-MFGM40); F = mixture of Lacprodan PL-20 and BM powder (4:6, wt/wt; Lac40). The scale bars indicate $50 \mu \mathrm{m}$.

materials for the preparation of emulsions contributed to a change in rheological behavior, with a coefficient of determination as listed in Table 4. Emulsions BMMFGM100, Lac100, and BM-MFGM40 showed a flow behavior more similar to Newtonian flow (index n was close to 1) and a very low shear stress against shear rates. In contrast, emulsions whey-MFGM100, wheyMFGM40, and Lac40 showed a shear-thinning behavior and gradually increasing shear stress against shear rates (Figure 4). This may probably have been due to the breakup of aggregates under the effect of a high shear rate (Dickinson and Golding, 1997). These results were consistent with the changes in the average droplet size of the emulsions with different materials (Table 3 ).

\section{The Adsorption Behavior of Proteins at the Oil-Water Interface, the $\Gamma_{P r o}$ and the $\Gamma_{P L}$}

The adsorption behavior of MFGM materials and mixtures of individual MFGM material and BMP in oil-in-water emulsions was studied by comparing the SDS-PAGE pattern of the cream phase with that of the serum phase (Figure 5). The relative proportion of in-

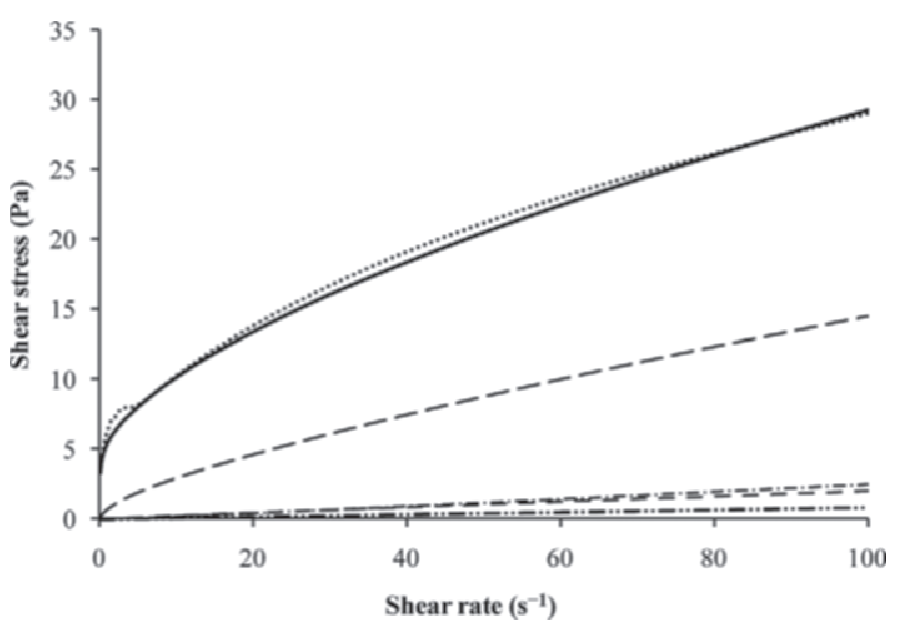

Figure 4. Flow curves of the emulsions prepared with microfiltered buttermilk [buttermilk (BM) milk fat globule membrane (BMMFGM100); - - - ] , microfiltered BM whey (whey-MFGM100; …), Lacprodan PL-20 (Lac100; Arla Foods Ingredients Group P/S, Viby, Denmark; ----), mixture of microfiltered BM and BM powder (4:6, wt/ wt; BM-MFGM40; - - -), mixture of microfiltered BM whey and BM powder (4:6, wt/wt; whey-MFGM40; - ), and mixture of Lacprodan PL-20 and BM powder (4:6, wt/wt; Lac40; ---). 
Table 4. Flow curve parameters ${ }^{1}$ of emulsions prepared with different emulsifying materials

\begin{tabular}{lccc}
\hline Emulsion $^{2}$ & $\begin{array}{c}\text { Shear stress } \\
{\left[\mathrm{K}\left(\mathrm{Pa} \cdot \mathrm{s}^{\mathrm{n}}\right)\right]^{3}}\end{array}$ & $\mathrm{n}^{3}$ & $\mathrm{R}^{2}$ \\
\hline BM-MFGM100 & $0.01 \pm 0.001^{\mathrm{a}}$ & $0.86 \pm 0.021^{\mathrm{cd}}$ & 0.99 \\
Whey-MFGM100 & $6.18 \pm 0.471^{\mathrm{b}}$ & $0.29 \pm 0.003^{\mathrm{a}}$ & 0.97 \\
Lac100 & $0.04 \pm 0.000^{\mathrm{a}}$ & $0.79 \pm 0.002^{\mathrm{c}}$ & $>0.99$ \\
BM-MFGM40 & $0.03 \pm 0.003^{\mathrm{a}}$ & $0.94 \pm 0.051^{\mathrm{d}}$ & 0.98 \\
Whey-MFGM40 & $5.72 \pm 0.516^{\mathrm{b}}$ & $0.33 \pm 0.058^{\mathrm{a}}$ & 0.97 \\
Lac40 & $0.63 \pm 0.042^{\mathrm{a}}$ & $0.68 \pm 0.007^{\mathrm{b}}$ & $>0.99$ \\
\hline
\end{tabular}

$\overline{\mathrm{a}-\mathrm{d}}$ Values within a column followed by different superscript letters are significantly different (Tukey test, $P \leq$ $0.05)$.

${ }^{1}$ Values \pm SD of 3 replicates.

${ }^{2}$ BM-MFGM100 = emulsion prepared with microfiltered buttermilk (BM) milk fat globule membrane (MFGM); whey-MFGM100 = emulsion with microfiltered BM whey; Lac100 = emulsion with Lacprodan PL-20 (Arla Foods Ingredients Group P/S, Viby, Denmark); BM-MFGM40 = emulsion with mixture of microfiltered BM and BMP (4:6, wt/wt); whey-MFGM40 = emulsion with mixture of microfiltered BM whey and BMP (4:6, $\mathrm{wt} / \mathrm{wt}) ; \mathrm{Lac} 40=$ emulsion with mixture of Lacprodan PL-20 and BMP (4:6, wt/wt).

${ }^{3} \mathrm{~K}=$ consistency index; $\mathrm{n}=$ flow behavior index

dividual adsorbed protein at the surface (cream phase) and the sum of protein in the cream phase and in the serum phase (i.e., in the original emulsion) was estimated by using color intensity analysis. The presence of $\mathrm{XO}, \mathrm{BTN}$, and caseins in whey-MFGM was negligible (Figure 1). Therefore, the adsorbed XO, BTN, and caseins of emulsion whey-MFGM100 were not taken into account. Among the remaining 5 emulsions, the BM-MFGM100 emulsion showed the lowest amount of $\mathrm{XO}$ and $\mathrm{BTN}$ in the adsorbed phase (lane 1 and $1^{\prime}$, Figure 5), occupying $40.3 \pm 1.8$ and $42.8 \pm 1.8 \%$ of the total adsorbed proteins, respectively (Figure 6). With whey-MFGM40 emulsions, all XO, BTN, and caseins were adsorbed onto the oil droplet. The intensities of adsorbed caseins, $\beta$-LG, and $\alpha$-LA of Lac100 and Lac40 emulsions were similar, whereas BM-MFGM40 contained greater amounts of adsorbed caseins compared with that of BM-MFGM100 (Figure 6).

The surface $\Gamma_{\text {Pro }}$ and $\Gamma_{\mathrm{PL}}$ of emulsions prepared with different MFGM materials are given in Table 5. The interfacial layer of emulsions probably consisted of a mixture of whey proteins, caseins, MFGM proteins, and polar lipids. The $\Gamma_{\mathrm{Pro}}$ of emulsions prepared at the same concentration of total protein $(2.3 \mathrm{~g} / 100 \mathrm{~g}$ of product), containing different MFGM proteins components, was significantly different from each other. This may indicate that the composition regarding caseins, whey proteins, and MFGM proteins in the emulsions was significantly different (Table 2 and Figure 1). With increasing polar lipids content in the emulsions (Table 1), the surface $\Gamma_{\mathrm{PL}}$ increased, except for wheyMFGM40 emulsions (Table 5). Among the 6 emulsions, the surface $\Gamma_{\text {Pro }}$ of whey-MFGM40 was highest compared with that of other emulsions, probably due to the presence of many large aggregates in these emulsions. Srinivasan et al. (1996) and Dickinson and Davies (1999) indicated that the addition of calcium chloride before emulsification increased the surface $\Gamma_{\text {Pro }}$; this could be attributed to the aggregation of caseins, due to binding with $\mathrm{Ca}^{2+}$, and subsequent adsorption of the aggregated caseins at the droplet surface. In addition, $\mathrm{Ca}^{2+}$ binding reduces charge repulsion between the

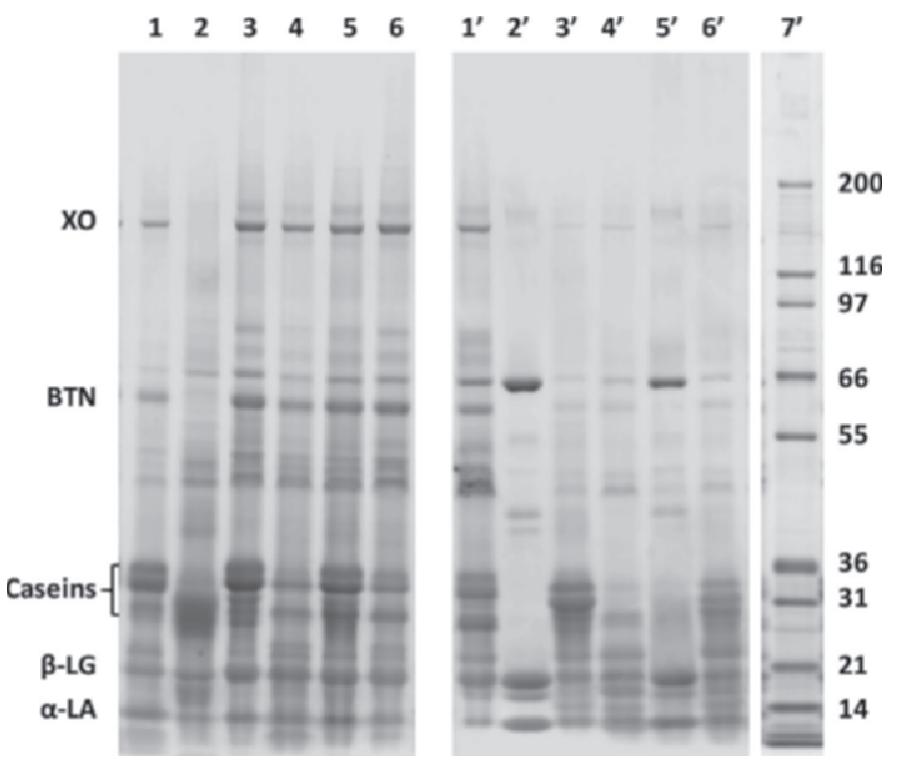

Figure 5. Sodium dodecyl sulfate PAGE patterns of different samples. Lanes 1 and $1^{\prime}=$ cream and serum phase of microfiltered buttermilk [buttermilk (BM) milk fat globule membrane (BM-MFGM100)], respectively; lanes 2 and $2^{\prime}=$ cream and serum phase of microfiltered BM whey (whey-MFGM100), respectively; lanes 3 and $3^{\prime}=$ cream and serum phase of Lacprodan PL-20 (Lac100; Arla Foods Ingredients Group P/S, Viby, Denmark), respectively; lanes 4 and $4^{\prime}=$ cream and serum phase of mixture of microfiltered BM and BM powder (4:6, wt/ wt; BM-MFGM40), respectively; lanes 5 and $5^{\prime}=$ cream and serum phase of mixture of microfiltered BM whey and BM powder (4:6, wt/ wt; whey-MFGM40), respectively; lanes 6 and $6^{\prime}=$ cream and serum phase of mixture of Lacprodan PL-20 and BM powder (4:6, wt/wt; Lac40), respectively; lane $7=$ molecular mass $(\mathrm{kDa})$ standards. The load on each lane contained $16 \mu \mathrm{g}$ of total protein. $\mathrm{XO}=$ xanthine oxidase; BTN = butyrophilin. 


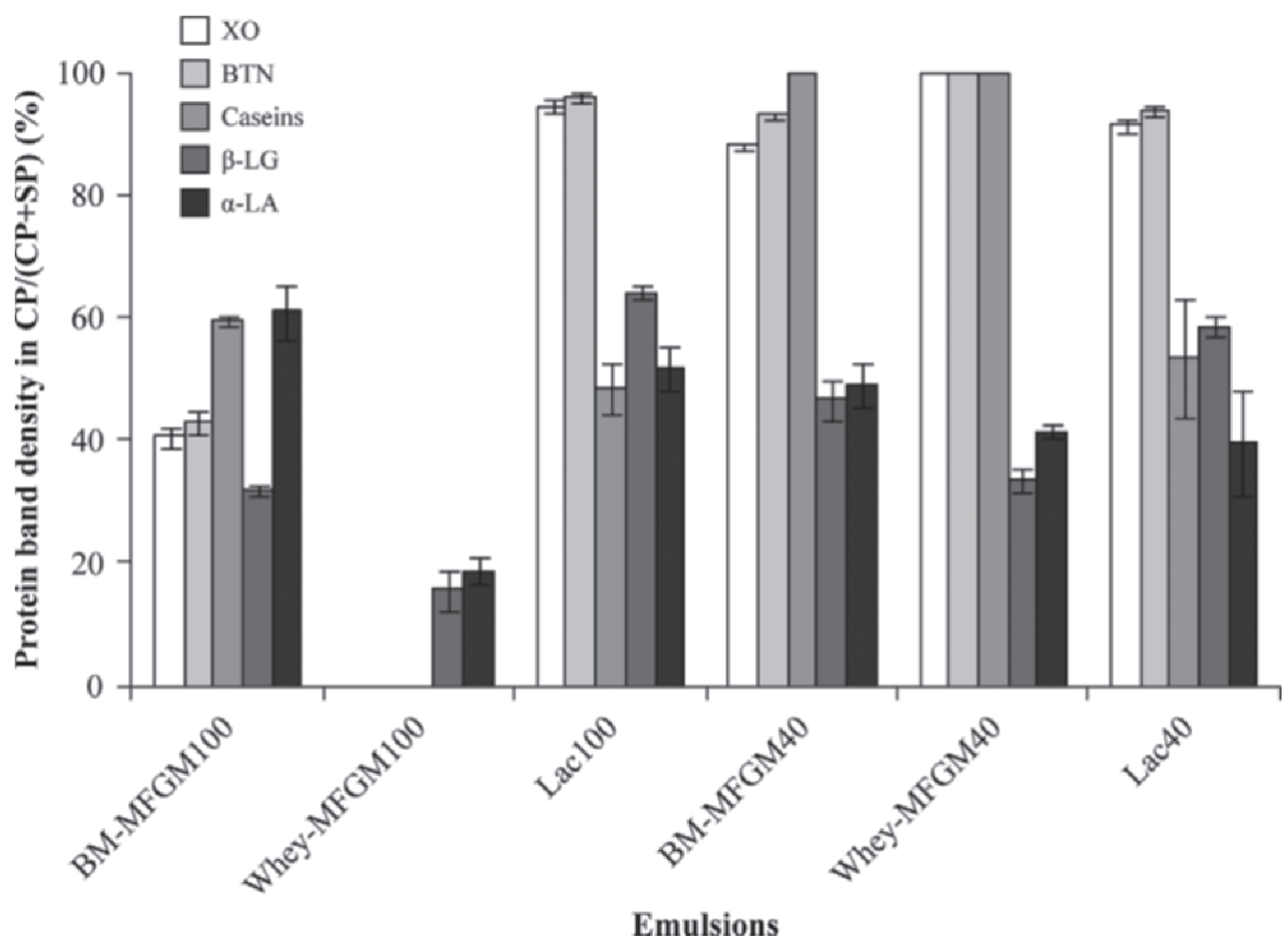

Figure 6. Sodium dodecyl sulfate PAGE band intensity of xanthine oxidase (XO), butyrophilin (BTN), caseins, $\beta$-LG, and $\alpha-\mathrm{LA}$ in the cream phase relative to the sum of those in the cream and serum of different emulsions; namely, emulsions prepared with microfiltered buttermilk [buttermilk (BM) milk fat globule membrane (BM-MFGM100)], microfiltered BM whey (whey-MFGM100), Lacprodan PL-20 (Lac100; Arla Foods Ingredients Group P/S, Viby, Denmark), mixture of microfiltered BM and BM powder (4:6, wt/wt; BM-MFGM40), mixture of microfiltered BM whey and BM powder (4:6, wt/wt; whey-MFGM40), and mixture of Lacprodan PL-20 and BM powder (4:6, wt/wt; Lac40). CP = cream phase; $\mathrm{SP}=$ serum phase.

casein molecules and hence can increase the protein packing at the interface. As mentioned, the concentration of $\mathrm{Ca}^{2+}$ could be high in whey-MFGM due to the fact that large amounts of proteins, mainly caseins, were already coagulated and precipitated during cheese making. Similar to the surface $\Gamma_{\text {Pro }}$, the highest $\Gamma_{\mathrm{PL}}$ was observed in the whey-MFGM40 emulsion, despite the fact that the polar lipids content in this emulsion was lower compared with whey-MFGM100, which also contained large aggregations. This can be explained by the difference in concentrations of polar lipids, minerals, MFGM-specific proteins, and ratio of casein and whey proteins. However, this phenomenon needs to be further investigated. Compared with all emulsions, the lowest surface $\Gamma_{\text {Pro }}$ and $\Gamma_{\mathrm{PL}}$ was observed for the BM-MFGM100 emulsions. This could be due to the strong interaction between MFGM material and other components (e.g., whey proteins and caseins) that may exist at the interface and because the polar lipids of MFGM may lower the interfacial tension; consequently, the particles remain individually dispersed in the emulsion. Corredig and Dalgleish (1998) found that the newly formed oil droplets covered by the MFGM material behaved differently from emulsions stabilized by other milk proteins [i.e., no displacement occurred upon the addition of a small-molecular-weight surfactant and the droplets were not affected by the presence of proteins (e.g., addition of $\beta-\mathrm{LG}$ or caseins)]. Results in the present study showed that no competitive displacement seemed to occur between proteins and polar lipids, but that the presence of components such as whey proteins, caseins, MFGM-specific proteins, and minerals and especially their concentrations were affected by these substances on the interfacial layer of the emulsions. To get a full understanding of the effect of different concentrations of polar lipids and proteins or possible interaction between them at the interface during emulsification or on possible competitive adsorption at the interface of the emulsion, further research with the same isolated MFGM source is needed.

\section{CONCLUSIONS}

The emulsifying and emulsion-stabilizing properties of MFGM materials were strongly influenced by their composition. The use of BM-MFGM (regardless of con- 
Table 5. The surface protein load $\left(\Gamma_{\mathrm{Pro}}\right)$ and polar lipids load $\left(\Gamma_{\mathrm{PL}}\right)$ of emulsions prepared with different milk fat globule membrane (MFGM) materials

\begin{tabular}{lcc}
\hline Emulsion $^{2}$ & $\Gamma_{\text {Pro }}\left(\mathrm{mg} / \mathrm{m}^{2}\right)$ & $\Gamma_{\mathrm{PL}}\left(\mathrm{mg} / \mathrm{m}^{2}\right)$ \\
\hline BM-MFGM100 & $5.24 \pm 0.12^{\mathrm{a}}$ & $0.18 \pm 0.005^{\mathrm{a}}$ \\
Whey-MFGM100 & $8.58 \pm 0.05^{\mathrm{c}}$ & $1.20 \pm 0.11^{\mathrm{c}}$ \\
Lac100 & $7.59 \pm 0.11^{\mathrm{b}}$ & $1.29 \pm 0.03^{\mathrm{c}}$ \\
BM-MFGM40 & $9.65 \pm 0.16^{\mathrm{d}}$ & $0.36 \pm 0.01^{\mathrm{a}}$ \\
Whey-MFGM40 & $17.96 \pm 0.70^{\mathrm{f}}$ & $1.93 \pm 0.15^{\mathrm{d}}$ \\
Lac40 & $11.37 \pm 0.03^{\mathrm{e}}$ & $0.71 \pm 0.07^{\mathrm{b}}$ \\
\hline
\end{tabular}

${ }^{\mathrm{a}-\mathrm{f}}$ Values within a column followed by different superscript letters are significantly different (Tukey test, $P \leq 0.05$ ).

${ }^{1}$ Mean values $\pm \mathrm{SD}$ of 3 replicates.

${ }^{2}$ BM-MFGM100 = emulsion prepared with microfiltered buttermilk (BM) milk fat globule membrane (MFGM); whey-MFGM100 = emulsion with microfiltered BM whey; Lac100 = emulsion with Lacprodan PL-20 (Arla Foods Ingredients Group P/S, Viby, Denmark); BMMFGM40 = emulsion with mixture of microfiltered BM and BMP (4:6, wt/wt); whey-MFGM40 = emulsion with mixture of microfiltered BM whey and BMP (4:6, wt/wt); Lac40 = emulsion with mixture of Lacprodan PL-20 and BMP (4:6, wt/wt).

centration) and Lacprodan PL-20 as emulsifiers resulted in emulsions with similar properties, characterized by a narrow particle size distribution pattern with a smaller $\mathrm{d}_{3,2}$, a very low viscosity, and a Newtonian-like flow behavior. Emulsions prepared with whey-MFGM alone as emulsifier contained the highest amount of polar lipids together with the presence of many large aggregates of droplets and showed shear-thinning behavior. Whey-MFGM did not have good emulsifying properties compared with other MFGM materials, despite the fact that it contained a higher concentration of polar lipids. This could be due to the high concentration of minerals (especially $\mathrm{Ca}^{2+}$ ) in the whey-MFGM. All results demonstrated that not only the polar lipids content but also the presence of other components (e.g., whey proteins, caseins, MFGM-specific proteins, and minerals), and especially the level of these substances and their possible interactions in the different MFGM materials, determined their emulsifying properties.

\section{ACKNOWLEDGMENTS}

This work was financially supported by a Ministry of Education and Training (MOET) scholarship of Vietnam. Arla Foods Ingredients Group P/S (Viby, Denmark) is acknowledged for providing Lacprodan PL-20. The authors also thank FrieslandCampina (Lummen, Belgium), and Büllinger Butterei NV (Büllinger, Belgium) for providing the buttermilk powder and whey buttermilk, respectively.

\section{REFERENCES}

AOAC (Association of Official Analytical Chemists). 1984. Official Methods of Analysis. AOAC, Arlington, VA.
Burling, H., and G. Graverholt. 2008. Milk-A new source for bioactive phospholipids for use in food formulations. Lipid Technol. $20: 229-231$.

Cano-Ruiz, M. E., and R. L. Richter. 1997. Effect of homogenization pressure on the milk fat globule membrane proteins. J. Dairy Sci. 80:2732-2739.

Corredig, M., and D. G. Dalgleish. 1997. Isolates from industrial buttermilk: Emulsifying properties of materials derived from the milk fat globule membrane. J. Agric. Food Chem. 45:4595-4600.

Corredig, M., and D. G. Dalgleish. 1998. Buttermilk properties in emulsions with soybean oil as affected by fat globule membrane derived proteins. J. Food Sci. 63:476-480.

Corredig, M., R. R. Roesch, and D. G. Dalgleish. 2003. Production of a novel ingredient from buttermilk. J. Dairy Sci. 86:2744-2750.

Dewettinck, K., R. Rombaut, N. Thienpont, T. T. Le, K. Messens, and J. Van Camp. 2008. Nutritional and technological aspects of milk fat globule membrane material. Int. Dairy J. 18:436-457.

Dickinson, E., and E. Davies. 1999. Influence of ionic calcium on stability of sodium caseinate emulsions. Colloids Surf. B Biointerfaces 12:203-212.

Dickinson, E., and M. Golding. 1997. Depletion flocculation of emulsions containing unadsorbed sodium caseinate. Food Hydrocoll. $11: 13-18$

Elling, J. L., S. E. Duncan, T. W. Keenan, W. N. Eigel, and J. Boling. 1996. Composition and microscopy of reformulated creams from reduced cholesterol butter oil. J. Food Sci. 61:48-53.

IDF (International Dairy Federation). 1986. Whey cheese-Determination of fat content-Röse-Gottlieb-gravimetric method. Standard 59A. IDF, Brussels, Belgium.

IDF (International Dairy Federation). 1993. Milk-Determination of nitrogen content. Standard 20B. IDF, Brussels, Belgium.

IDF (International Dairy Federation). 2004. Whey cheese-Determination of dry matter. Standard 58. IDF, Brussels, Belgium.

Kanno, C. 1989. Emulsifying properties of bovine milk fat globule membrane in milk fat emulsion: Conditions for the reconstitution of milk fat globules. J. Food Sci. 54:1534-1539.

Kanno, C., Y. Shimomura, and E. Takano. 1991. Physicochemical properties of milk fat emulsions stabilized with bovine milk fat globule membrane. J. Food Sci. 56:1219-1223.

Le, T. T., J. Miocinovic, T. M. Nguyen, R. Rombaut, J. Van Camp, and K. Dewettinck. 2011a. Improved solvent extraction procedure and HPLC-ELSD method for analysis of polar lipids from dairy materials. J. Agric. Food Chem. 59:10407-10413.

Le, T. T., J. van Camp, P. A. L. Pascual, G. Meesen, N. Thienpont, K. Messens, and K. Dewettinck. 2011b. Physical properties and microstructure of yoghurt enriched with milk fat globule membrane material. Int. Dairy J. 21:798-805.

Le, T. T., J. Van Camp, R. Rombaut, F. van Leeckwyck, and K. Dewettinck. 2009. Effect of washing conditions on the recovery of milk fat globule membrane proteins during the isolation of milk fat globule membrane from milk. J. Dairy Sci. 92:3592-3603.

Mather, I. H. 2000. A review and proposed nomenclature for major proteins of the milk-fat globule membrane. J. Dairy Sci. 83:203247.

McCrae, C. H., A. J. R. Law, and J. Leaver. 1999. Emulsification properties of whey proteins in their natural environment: Effect of whey protein concentration at 4 and $8 \%$ milk fat. Food Hydrocoll. 13:389-399.

Phan, T. T. Q., M. Asaduzzaman, T. T. Le, E. Fredrick, P. Van der Meeren, and K. Dewettinck. 2013. Composition and emulsifying properties of a milk fat globule membrane enriched material. Int. Dairy J. 29:99-106.

Roesch, R. R., A. Rincon, and M. Corredig. 2004. Emulsifying properties of fractions prepared from commercial buttermilk by microfiltration. J. Dairy Sci. 87:4080-4087.

Rombaut, R., V. Dejonckheere, and K. Dewettinck. 2006. Microfiltration of butter serum upon casein micelle destabilization. J. Dairy Sci. 89:1915-1925.

Rombaut, R., V. Dejonckheere, and K. Dewettinck. 2007a. Filtration of milk fat globule membrane fragments from acid buttermilk cheese whey. J. Dairy Sci. 90:1662-1673. 
Rombaut, R., and K. Dewettinck. 2007b. Thermocalcic aggregation of milk fat globule membrane fragments from acid buttermilk cheese whey. J. Dairy Sci. 90:2665-2674.

Scholey, A. B., D. A. Camfield, M. E. Hughes, W. Woods, C. K K. Stough, D. J. White, S. V. Gondalia, and P. D. Frederiksen. 2013. A randomized controlled trial investigating the neurocognitive effects of Lacprodan ${ }^{\circledR}$ PL-20, a phospholipid-rich milk protein concentrate, in elderly participants with age-associated memory impairment: The Phospholipid Intervention for Cognitive Ageing Reversal (PLICAR): Study protocol for a randomized controlled trial. Trials 14:404-419.

Singh, H. 2006. The milk fat globule membrane-A biophysical system for food applications. Curr. Opin. Colloid Interface Sci. 11:154163

Singh, H. 2011. Aspects of milk-protein-stabilised emulsions. Food Hydrocoll. 25:1938-1944.

Sodini, I., P. Morin, A. Olabi, and R. Jiménez-Flores. 2006. Compositional and functional properties of buttermilk: A comparison between sweet, sour, and whey buttermilk. J. Dairy Sci. 89:525-536.

Srinivasan, M., H. Singh, and P. A. Munro. 1996. Sodium caseinatestabilized emulsions: Factors affecting coverage and composition of surface proteins. J. Agric. Food Chem. 44:3807-3811.

Swaisgood, H. E. 1992. Chemistry of the caseins. Pages 63-110 in Advanced Dairy Chemistry: Volume I: Proteins. 2nd ed. P. F. Fox, ed. Elsevier Applied Science, London, UK.
Tomas, A., and D. Paquet. 1994. Effect of fat and protein contents on droplet size and surface protein coverage in dairy emulsions. J. Dairy Sci. 77:413-417.

Vanderghem, C., P. Bodson, S. Danthine, M. Paquot, C. Deroanne, and C. Blecker. 2010. Milk fat globule membrane and buttermilks: From composition to valorization. Biotechnol. Agron. Soc. Environ. 14:485-500.

Voutsinas, L. P., E. Cheung, and S. Nakai. 1983. Relationships of hydrophobicity to emulsifying properties of heat denatured proteins. J. Food Sci. 48:26-32.

Wong, P. Y. Y., and D. D. Kitts. 2003. A comparison of the buttermilk solids functional properties to nonfat dried milk, soy protein isolate, dried egg white, and egg yolk powders. J. Dairy Sci. $86: 746-754$.

Ye, A. 2010. Surface protein composition and concentration of whey protein isolate-stabilized oil-in-water emulsions: Effect of heat treatment. Colloids Surf. B Biointerfaces 78:24-29.

Ye, A., S. G. Anema, and H. Singh. 2004. High-pressure-induced interactions between milk fat globule membrane proteins and skim milk proteins in whole milk. J. Dairy Sci. 87:4013-4022. 